MUSICA THEORICA 201715

SCIENTIFIC ARTICLE

Data do recebimento: $21 / 07 / 2017$

Data da aprovação final: 25/01/2018

\title{
A Emergência do Sujeito na Narrativa do Prelúdio Op. 28 no 14 de Chopin
}

\author{
The Emergency of the Subject in the Narrative \\ of Chopin's Prelude Op. 28 no 14
}

\author{
Vinícius Fernandes \\ Universidade de São Paulo - ECA \\ viniciusfersil@gmail.com
}

\section{Guto Brambilla}

Universidade de São Paulo - ECA

gutobrambilla@usp.br

\section{Fernando Iazzetta}

Universidade de São Paulo - ECA

iazzetta@usp.br

Resumo: Tomando como baliza epistemológica a teoria de narratividade musical de Byron Almén, empreendeu-se uma análise do Prelúdio para piano, op. 28 no 14 de Frederick Chopin. Entendemos esta composição como uma polifonia a duas vozes, constituída a partir da interdependência contrapontística entre elas. Percebeu-se um esforço de autonomização melódica, alcançada apenas nos últimos compassos. Concluiu-se que este processo constitui o núcleo do conflito narrativo. Sob este escopo, a estrutura desta peça revelou-se emblemática na expressão de uma questão capital à poética romântica: a urgência da emergência do sujeito diante de forças integrativas associadas a uma determinada hierarquia, seja ela política, social ou, em última instância, metafísica.

Palavras-chave: análise narrativa; teorias da narratividade musical; semiótica musical; romantismo.

Abstract: Taking the musical narrative theory of Byron Almén as epistemological referential, we propose an analysis of the Prelude for piano, op. 28 no 14 by Frederick Chopin. We understand this composition as a two voices polyphony, constituted by the contrapuntal interdependence between them. We tracked an effort for melodic autonomy, achieved only in the last few bars. We concluded that this process constitutes the core of the narrative conflict. Under this scope, the

\section{MUSICA THEORICA}


structure of this piece revealed itself emblematic in the expression of a fundamental quest in the romantic poetics: the urgency of the subject emergence in face of integrative forces associated with a given hierarchy, be it political, social or, ultimately, metaphysical.

Keywords: analysis of narrative; theories of musical narrativity; musical semiotics; romanticism.

\section{1 - Introdução}

As fundações das teorias da narratividade na música apoiam-se, em grande medida, sobre estudos correlatos no campo da literatura e linguística. Entretanto, os musicólogos que atuam nesta área têm empreendido investigações acerca das idiossincrasias da narratividade musical a fim de fundamentar um campo epistemológico próprio. Assim, mesmo mobilizando operadores conceituais que não foram criados para descrever fenômenos musicais, pesquisadores como Eero Tarasti, Byron Almén e Michael L. Klein contribuíram para a consolidação de um campo de estudos que permitiu grande avanço no desenvolvimento de ferramentas analíticas utilizadas para o estudo da narratividade musical. Almén (2008, p.21), sobre Tarasti, afirma:

As análises de Tarasti, através de seu cuidadoso desenredar de diferentes elementos expressivos, reforçam fortemente minha posição de que narrativas literárias e musicais exibem importantes distinções em suas manifestações. Uma análise tarastiana "não é um comentário literário - a 'história' que esta composição pode estar contando -, mas sim é uma reflexão sobre as estruturas semio-musicais que tornam possível seus conteúdos psicológicos concretos.

O autor evidencia, dessa maneira, a necessidade do estabelecimento das dinâmicas e elementos específicos em ação na narrativa musical, a fim de proporcionar métodos para aferir as estruturas globais da mesma. Para isso, torna-se fundamental assinalar os pontos de convergência e divergência das teorias da narratividade musical com as teorias da narratividade literária na metodologia de Almén.

\section{2 - A isotopia greimasiana em Eero Tarasti}

O método analítico proposto por Eero Tarasti em seu livro "A Theory of Musical Semiotics" baseia-se fundamentalmente na semiótica do linguista Algirdas Julius Greimas. Um conceito chave de seu pensamento, importado por Tarasti, é a ideia de isotopia. Analisando-o, Leite (2009, p. 124), esclarece:

Isotopia é um termo que migrou da Física para a Semiótica. Usado, naquela, para designar propriedade de elementos que possuem o mesmo número atômico, mas

\section{MUSICA THEORICA}


cujos números de massa são distintos, nesta, foi definida, a princípio, no âmbito da semântica estrutural de A. J. Greimas (1973) como a iteração de semas ao longo de uma cadeia sintagmática. Segundo o semioticista, essa iteração é efetuada pelos elementos de significação e não pelas palavras, pelas figuras e não pelos signos. Haveria, assim, traços que se reiteram, repetem-see são recorrentes ao longo do enunciado, cuja função seria assegurar a coesão semântica e a homogeneidade do discurso enunciado.

Amplificando o valor dos elementos de significação e das figuras na construção discursiva, em detrimento das palavras e dos signos, o conceito de isotopia pode ser expandido do campo estritamente linguístico para outras áreas da comunicação humana, tornando-se adequado para operar como instrumento analítico de outros tipos de manifestações semióticas, como por exemplo, no nosso caso, a música.

A "iteração de semas ao longo de uma cadeia sintagmática" presente na isotopia fundamenta um processo crucial quando nos debruçamos analiticamente sobre um fenômeno que se desdobra temporalmente como a música: a redundância semântica. Klinkenberg (apud. Leite 2009), atribui esta proprieda de da isotopia ao princípio de economia semiótica, já que todo elemento de um enunciado se inscreve no contexto criado pelos elementos que o precedem, diminuindo, assim, o custo semiótico da leitura. Dessa forma, novas informações são produzidas quando determinados elementos reaparecem no discurso iluminados pelos seus predecessores. A isotopia, portanto, garante a manutenção da coerência semântica, assegurando a continuidade temática e figurativa por meio de elementos repetidos de uma frase a outra (Leite, 2009).

A metodologia de Almén é fortemente influenciada pela teoria da narratividade musical de Tarasti, consequentemente, isotopia é um conceito central em suas análises. O primeiro passo para uma análise tarastiana é a segmentação da obra musical em isotopias. Cada isotopia assume um papel dinâmico dentro de categorias discursivas, que correspondem, ou a parâmetros musicais tradicionais como registro, ritmo, harmonia, etc. ou a outros processos de organização temporal como memória, expectativa ou a transformação de temas e motivos (Almén, 2008). Sobre a análise da atividade das isotopias em uma peça musical, Almén (2008, p. 21) afirma:

Os processos dinâmicos - intrínsecos a cada isotopia - afetam e influenciam-se mutuamente por meio das modalidades, refletindo flutuações no nível de atividade, movimento dirigido em direção a um fim, quantidade de informação disponível ao ouvinte, cumprimento de obrigações formais ou discursivas, e grau de exibição performativa.

Assim, sob esta perspectiva, a isotopia torna-se o bloco constitutivo da narrativa musical. Sendo sua identificação, crucial para empreender uma análise musical consistente em níveis estruturais mais elevados. 


\section{3 - Crise hierárquica}

Uma das mais célebres definições de narrativa, fundamentada na crítica literária, foi proposta por Tzvetan Todorov. Nela, o autor enuncia que, em uma narrativa,

a intriga mínima consiste na passagem de um equilíbrio a outro. Uma narrativa ideal começa por uma situação estável que uma força qualquer vem perturbar. Daí resulta um estado de desequilíbrio; por ação de uma força dirigida em sentido inverso, o equilíbrio é restabelecido; o segundo equilíbrio é semelhante ao primeiro, mas os dois nunca são idênticos. Há, por conseguinte, dois tipos de episódios na narrativa: os que descrevem um estado (de equilíbrio ou de desequilíbrio) e os que descrevem a passagem de um estado a outro (Todorov 1971, p. 124).

Um ponto importante que deve ser assinalado nesta formulação é o fato de que o equilíbrio inicial não é restituído ao final, mas sim restabelecido em outros termos. Neste sentido, tendo em mente o amplo espectro de possibilida des semânticas que estas diferentes fases narrativas podem incorporar, é evidente que não há necessidade de que os equilíbrios assumam uma valência positiva, podendo, inclusive, ser o equilíbrio, completamente indesejável ao leitor/espectador.

Da estrutura arquetípica de uma narrativa descrita por Todorov, Almén se concentrará na interação entre forças disruptivas e algum tipo de ordem que reluta em ser alterada. Para ele, "é melhor entender uma narrativa tanto mostrando sua organização de relações hierárquicas sujeitadas à uma crise como traçando as consequências desta crise" (Almén 2008, p.22). Apesar desta asserção revelar a incorporação da dinâmica equilíbrio-desequilíbrio de alguma forma em sua teoria, para Almén, o esquema de Todorov falha ao prever que há necessariamente um desfecho para toda e qualquer narrativa. Ele afirma que acredita "reconhecer que uma narrativa pode resolver-se de forma indesejável ou até não se resolver é tão crucial à teoria da narratividade musical quanto à teoria da narratividade literária" (Almén 2008, p.22)

A centralidade da crise hierárquica na metodologia analítica de Almén vem da semiótica de narrativas míticas proposta James Jakób Liszka. O autor postula que:

a narração foca em um conjunto de regras de um certo domínio ou domínios da vida cultural que definem uma certa [...] hierarquia e as coloca em uma crise. Há uma disrupçãona função normativa destas regras - elas são violadas, há algum tipo de transgressão. A narrativa então se desdobra em uma certa, de alguma forma ambivalente, resolução dessas crises, dependendo da pragmática do conto: a hierarquia rompida é destruída, levando a anomia social ou a consequências terrivelmente trágicas [...] A ambivalência da resolução revela a

\section{MUSICA THEORICA}


presença de uma certa tensão que serve como dinâmica da narrativa, a tensão entre uma ordem ou hierarquia, isto é, um conjunto de regras que impõe uma ordem em uma cultural, e a possibilidade de sua transgressão, ou seja, a possibilidade de uma ordem alternativa (Liska apud Almén 2009, p. 73-74).

Almén defende que o modelo proposto por Liska pode descrever peças musicais tão adequadamente como narrativas míticas, já que os fenômenos musicais podem ser organizados em hierarquias implícitas e explícitas de diversas maneiras (Almén, 2008).

Liska determina um sistema de classificação dos conflitos entre a hierarquia que impõem uma ordem e o elemento transgressor desta hierarquia. Para ele, este conflito pode ser expresso a partir de duas oposições binárias: ordem/transgressão e vitória/derrota. A permutação dessas oposições define os quatro possíveis arquétipos narrativos (Tab. 3-1).

\begin{tabular}{|c|c|c|}
\hline Arquétipo & Vitória & Derrota \\
\hline Narrativa romance $^{1}$ & Hierarquia & \\
\hline Narrativa trágica & & Narrativa \\
\hline Narrativa irônica & & Hierarquia \\
\hline Narrativa cômica & Transgressão & \\
\hline
\end{tabular}

Tabela 1: Arquétipos narrativos de Liska

É importante frisar que nesse quadro, apesar da vitória da hierarquia/transgressão implicar na derrota de sua contraparte, o foco narrativo na polarização entre vitória e derrota é determinante para classificar qual tipo de arquétipo se aplica ao objeto de análise.

Sobre a classificação de Liska, Klein (2009, p. 105-106) explica:

Na comédia [narrativa cômica], um herói transgride uma ordem indesejada, a qual é transformada pela vitória do mesmo. No romance, o herói incorpora uma ordem e sua vitória sobre uma transgressão (mal) serve para sublinhar a desejabilidade desta ordem. Na tragédia, o herói pode oferecer uma nova e desejável ordem, mas ao estabelece-la, ele transgride uma ordem moral mais elevada que acaba levando-o a sua derrota. Finalmente, na ironia, o herói incorpora uma ordem tão desgastada por contradições que a ação heroica tornase impossível. Em uma narrativa, os valores de um herói e de uma ordem cultural estão sempre em jogo, esperando a vitória ou derrota que vai promove-los ou negá-los .

1 Optamos por não traduzir este arquétipo para "narrativa romântica" já que seu campo semântico é referenciado pelo gênero literário romance e não pelas manifestações artísticas, filosóficas e poéticas do romantismo, reforçando assim o enfoque funcional destes operadores conceituais de Liska. 
Almén (2008, p. 75) insiste que esta classificação não tem função estritamente taxonômica, mas também:

\begin{abstract}
fornece uma justificativa e explicação funcional para a organização narrativa em um meio temporal. Ao traçar as trajetórias narrativas em obras musicais, nós estamos observando estratégias que se aplicam em qualquer área na qual hierarquias divergentes são postas umas contra as outras, sejam elas políticas, sociais, interpessoais, psicológicas ou ideológicas.
\end{abstract}

\title{
4 - Níveis de operação
}

Tanto Tarasti como Liska distinguem diferentes níveis de operação ao empreender uma análise narrativa (apropriados pela metodologia analítica de Almén). Alguns deles apresentam algumas similaridades na sua formulação conceitual, permitindo uma aproximação teórica.

O nível mais baixo de análise de Liska é o agencial. Nele, considerando que estamos tratando da análise de narrativas musicais, as unidades musicosemânticas são identificadas, caracterizadas e localizadas no tempo. Podemos aproximá-lo do conceito de isotopia, mobilizado da semiótica Greimasiana para o campo musical por Tarasti.

No próximo nível, o analista avalia as relações dinâmicas entre as isotopias identificadas na peça. Mira-se as funções expressivas que cada uma delas exerce em relação à trajetória narrativa. Liska emprega, para este nível, o termo actantial, traduzido neste artigo como atorial. Pode-se aproximá-lo à ideia de modalidade empregada por Tarasti, mais uma vez, via Greimas. Através dela, a "atividade" das isotopias é imbuída de significado ao interpretar esta atividade em relação a um ambiente (Tarasti apud. Almén, 2008).

O último nível de análise diz respeito à interação das unidades expressiva s com as tensões entre a hierarquia que impõe uma ordem e a transgressão desta hierarquia. Neste sentido, é fundamental que o conflito na peça analisada seja identificado e que suas consequências sejam traçadas. Almén (2008, p.23) defende que "é o conflito - que projeta o discurso para além das condições iniciais - que propulsiona a narrativa para frente e dá à peça sua lógica psicológica e estética".

\section{5 - Prelúdio para piano Op. 28 № 14 de Chopin: Um panorama teórico}

Ao debruçar-se sobre esta peça, um primeiro aspecto que vem à tona, considerando algumas das análises já realizadas sobre este prelúdio, é a 
diversidade de tratamentos possíveis que podem ser dados a ela, ora considerada monofônica, ora homofônica, ou ainda possuindo um certo grau de desenvolvimento polifônico, como se pode verificar nos trabalhos de Marilyn Anne Meier (1993), Anatole Leikin (2015), Aeron Ogden (2009) e Alson Hood (2014). Esta questão é de suma importância para o desenvolvimento da análise narrativa empreendida por este estudo. A fim de explorar esse aspecto, expõe-se aqui as definições desses conceitos:

- Monofonia: é definida como uma melodia simples sem acompanhamento. Uma textura pode ser monofônica mesmo quando executada por mais de um instrumento em intervalos de uma ou mais oitavas.

- Polifonia: a textura polifônica ou contrapontística é a combinação de duas ou mais melodias, de modo que não há distinção clara entre melodia e acompanhamento.

- Homofonia: a textura homofônica é o cruzamento entre texturas monofônicas e polifônicas, dado que normalmente existe uma melodia clara acompanhada de vozes adicionais. Os acompanhamentos podem ser altamente variados; a textura de coro vertical, ou acordes em bloco, constitui um dos tipos mais simples de homofonia, nas quais as vozes acompanhantes estão ritmicamente alinhadas com a voz principal, que geralmente aparece no registro mais alto.

À primeira vista, o Prelúdio № 14 de Chopin aparenta ser uma peça predominantemente homofônica, principalmente quando empregadas análises descritivas, focadas na performance e nas técnicas pianísticas. Sobre este prelúdio, Meier (1993, p. 128-132) afirma ser ele:

uma peça basicamente em uníssono, que Chopin enriquece com grande expressividade. $\mathrm{O}$ esquema harmônico é arpegiado, consistindo em rápidas e simétricas tercinas oitavadas no registro grave do piano [...] Considerações sobre os planos frontal e de fundo são desnecessárias, uma vez que marcações de crescendo marcadoe o diminuendo resultam em certas notas que soam mais fortes do que outras.

Anatole Leikin (2015, p. 111-113) destaca que este Prelúdio é, ao lado do final da Sonata em Si bemol menor Op. 35, os dois únicos exemplos na obra de Chopin compostos inteiramente em oitavas paralelas, cujas tessituras correspondem à do violoncelo e exibem uma riqueza de linhas melódicas ocultas, 
típicas nos trabalhos monofônicos de Bach. Leikin continua a sua análise afirmando que a melodia única do Prelúdio № 14 contém duas linhas melódicas ocultas que revelam fragmentações temáticas principalmente nas vozes superiores e inferiores, entretanto menos polifonicamente desenvolvida do que o final da Sonata em Si bemol menor Op. 35.

Aeron Ogden (2009) por sua vez, além de acrescentar comparações com o Prelúdio № 20 (em Dó menor), no âmbito harmônico e no estilístico com o Prelúdio № 19 (em Mi bemol maior), faz breves análises quanto às questões de andamento, tessitura e registro, estado de espírito proposto pela peça e à estrutura melódica da peça, a qual ele define como ritmos triádicos, aplicados em forma de arpejos:

\begin{abstract}
Estou evitando conscientemente o termo tercina, por causa das convenções e associações relacionadas com o seu uso. O Prelúdio № 19 certamente emprega o uso de tercinas nos moldes tradicionais; mas o Prelúdio № 14 evita o padrão de acentuação comum, assim evitando o surgimento de uma linha melódica através da primeira nota de cada tercina como normalmente ocorre. A falta de qualquer mudança rítmica na peça e a ausência de padrões rítmicos de "3 sobre 2", confirma essa decisão. Na edição da peça de Schimer (1915), de fato, não é utilizada a notação em forma de tercinas, mas através do agrupamento de três colcheias (Ogden 2009, p. 4).
\end{abstract}

Desta forma, Ogden revela seis padrões diferentes de arpejos em ritmos triádicos, que são organizados em grupos de quatro e utilizados de maneira estrutural na composição do Prelúdio № 14. Assim, dando ênfase à uma proposta analítica horizontal, proporciona uma visão mais detalhada sobre o papel da condução de vozes e da tensão melódica na emersão de uma linha melódica como o fio condutor da peça e como esta linha atua na sua organização tonal.

Partindo para uma análise com enfoque mais estrutural, Alson Hood (2014), que não se preocupa com a definição homofonia/polifonia, aplica os conceitos de padrões lineares de intervalo (linear intervallic patterns), repetições ocultas (hidden repetition), deslocamento, agrupamento, ambiguidade rítmica, dinâmica e forma, para exemplificar como o ritmo e as estruturas tonais são indissociáveis no pensamento compositivo de Chopin nestes prelúdios. Em sua análise, Hood além de direcionar foco para as questões métricas ou polimétricas, também expõe como o sentido de direção tonal é proporcionado pelos padrões lineares de intervalo, utilizando gráficos schenkerianos para determinar principalmente as estruturas dos planos frontal e de fundo, identificando atividades motívicas nas vozes da melodia e do baixo, bem como a interação entre elas. 


\section{6 - Análise narrativa do Prelúdio para piano Op. 28 № 14}

Seguindo a metodologia proposta pela teoria da narratividade musical de Almén, o primeiro passo para análise narrativa dessa peça constitui-se pela definição dos seus respectivos níveis de operação: o nível agencial ou as isotopias, que possuem a função de unidades expressivas; o nível atorial, que definirá a maneira como as isotopias interagem; e o nível de avaliação da interação dessas unidades expressivas com a dinâmica ordem-transgressão, assim como suas consequências, a fim de enquadrá-la em um dos arquétipos narrativos supracitados.

\subsection{Nível agencial - Isotopias}

Como dito anteriormente, em uma primeira leitura essa peça não aparenta conter oposições entre melodia e acompanhamento, ou melodia e harmonia (acordes), uma vez que é composta por uma única melodia, executada pelas duas mãos, separadas por uma oitava, ambas contendo as mesmas indicações de expressão e dinâmica. Devido ao caráter angular da melodia, optou-se pela separação das vozes por registro, para a definição do nível agencial.

Tal opção se mostrou eficiente para os propósitos desta análise narrativa, pois revelou duas isotopias com morfologias características: no plano grave, o baixo apresenta um perfil intervalar bastante angular; no registro mais agudo, uma melodia, formada preponderantemente por graus conjuntos, diatônicos e cromáticos, bem como apresentando um desenvolvimento motívico-temático.

\subsection{Nível atorial}

Nesse nível, determinam-se as relações dinâmicas entre as isotopias e entre estas e o fluxo narrativo. Do primeiro ao penúltimo compasso, a oposição rítmica entre as isotopias estabelecidas permanece inalterada, contendo uma relação contrapontística de 2:1 e 1:2 entre elas, articulada pelos sinais de expressão e dinâmica, justificando o tratamento da peça como uma narrativa polifônica, proposta por este artigo. As indicações de dinâmica são essenciais para a definição do motivo principal Dó bemol - Si bemol - Dó bemol, na melodia, pois a primeira classe de altura é executada em crescendo e a segunda em diminuendo, deixando claro o destaque de uma em detrimento da outra (vide Figura 1). 


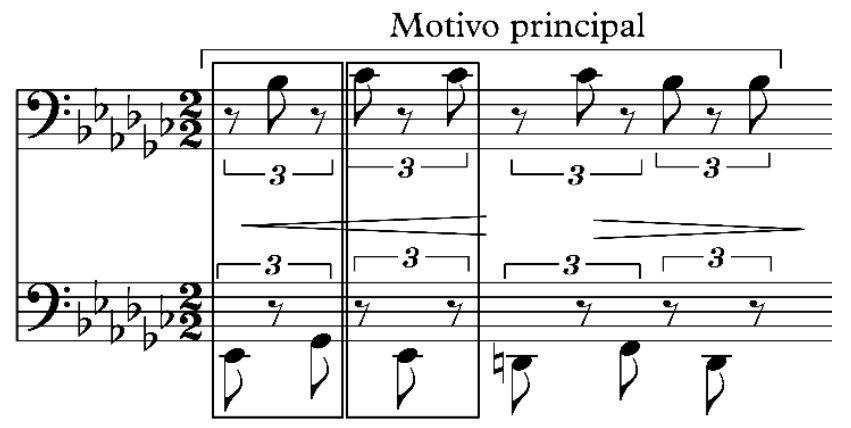

Figura 1: Compasso 1 - Motivo principal e articulação rítmica

Estabelecida a dinâmica inicial entre as isotopias, verifica-se que após a exposição do motivo principal, a tensão gerada pela oposição rítmica é ampliada através de cromatismos, adicionando instabilidade harmônica, além de caracterizar de forma mais pungente o contorno melódico. Nota-se que a melodia, ao tentar se destacar, frustra o movimento estabelecido pelo motivo principal com um movimento ascendente, sendo prontamente perseguido pelo baixo (ver Figura 2), chegando ao ápice da tensão, representado pelo próprio motivo principal, transposto para a região da dominante (ver Figura 3).

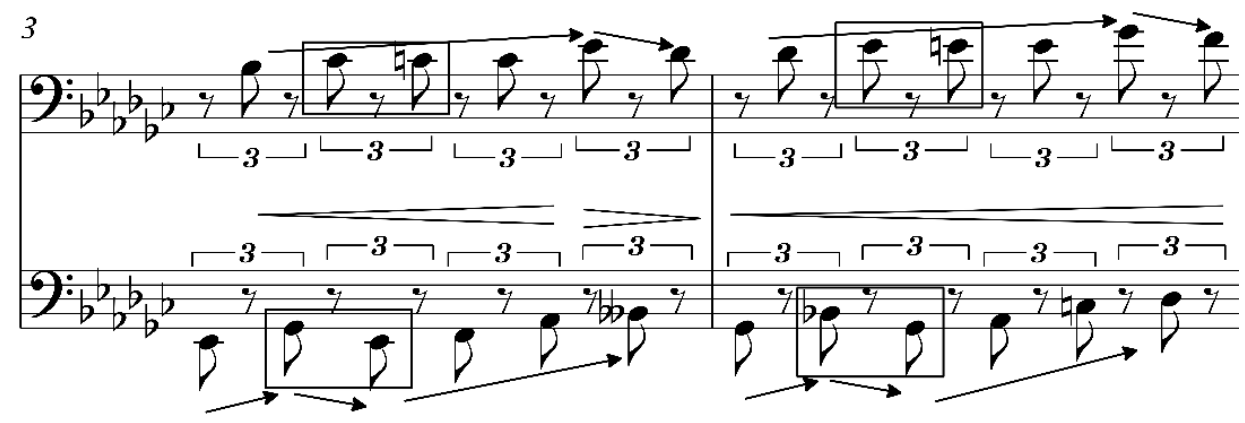

Figura 2: Compassos 3-4 - Aumento da tensão entre as isotopias

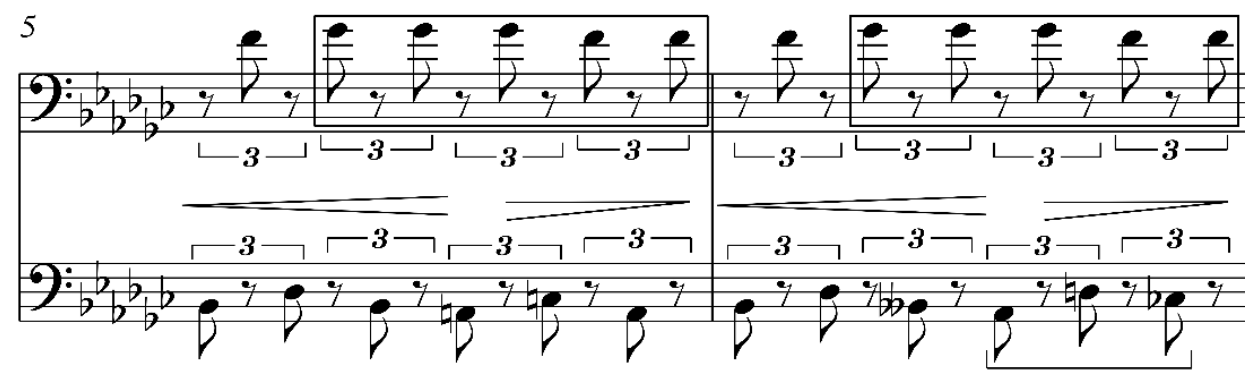

Figura 3: Compassos 5-6 - Ápice da tensão entre as isotopias - Motivo principal transposto para a região dominante 
Após estes compassos, a presença de intervalos cromáticos aumenta a desestabilização da tonalidade, tornando-a menos definida. Este fenômeno, somado à inversão das indicações de dinâmica, de cresc. - dim. para dim. - cresc., contribui para a produção de uma desorientação narrativa neste trecho. Vale ressaltar nestes compassos também a frase descendente que encaminha a narrativa para o estado inicial, preparando a reapresentação do motivo principal (vide Figura 4).

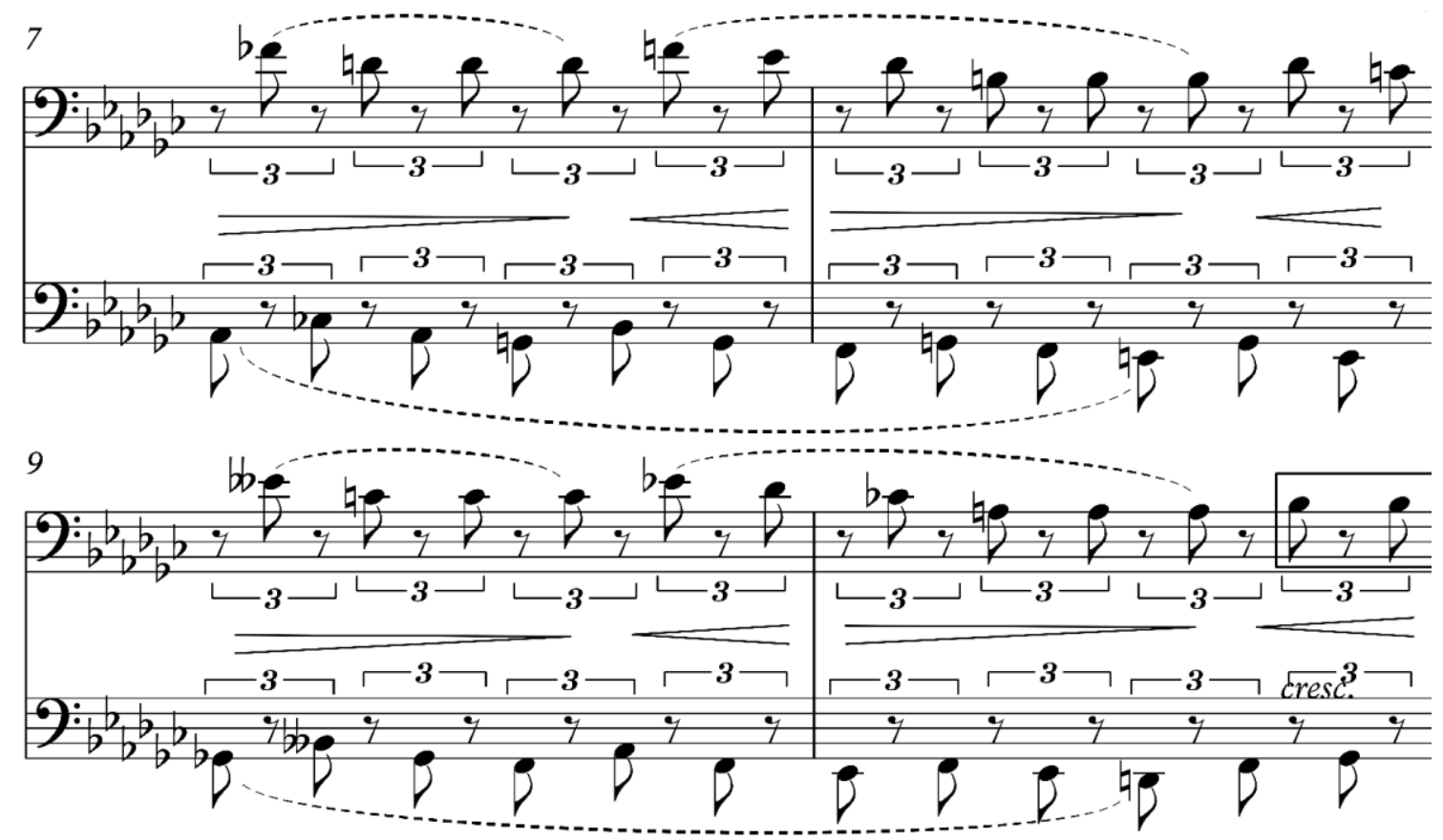

Figura 4: Compassos 7-10 - Desestabilização tonal e frase descendente preparando o retorno do motivo principal

Ambas isotopias voltam ao motivo principal, reestabelecendo o ambiente inicial da peça, porém em outro nível, pois os ânimos já não são mais os mesmos, uma vez que neste momento a relação entre ambas se dá em fortíssimo. Outra novidade é a alteração no perfil dinâmico do motivo principal de Dób - Sib - Dób para Sib - Dób - Sib. Na exposição do motivo, o tema se inicia com uma nota Sib, porém executada com dinâmica piano, além de ser a primeira de um crescendo, entretanto, na volta do mesmo motivo, essa mesma nota Sib vem de um impulso anterior, também em crescendo, mas agora é a primeira a ser executada em fortíssimo, garantindo a impressão da alteração do perfil dinâmico do motivo (vide Figura 5). 


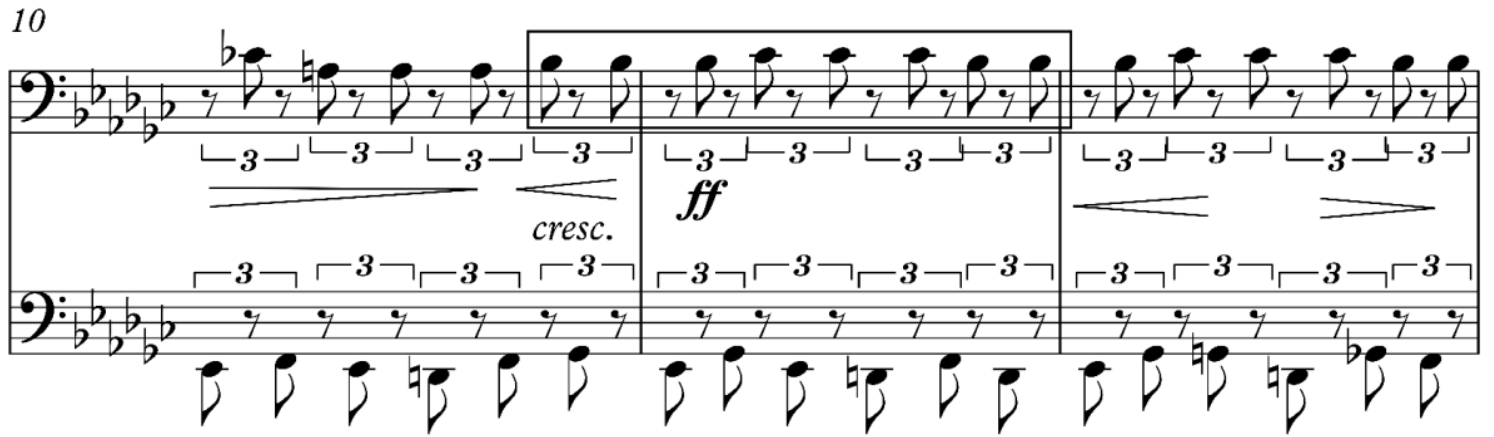

Figura 5: Compassos 10-12 - Alteração do perfil dinâmico do motivo principal

Após a volta ao motivo principal, a melodia empreende uma segunda tentativa de se desvencilhar do baixo, mas desta vez de maneira mais linear, ameaçando voltar para a região dominante, porém ao final executa um salto descendente de $4^{\underline{a}}$ aumentada, impelindo o baixo a voltar para a tônica da peça, também com um movimento descendente (vide Figura 6).

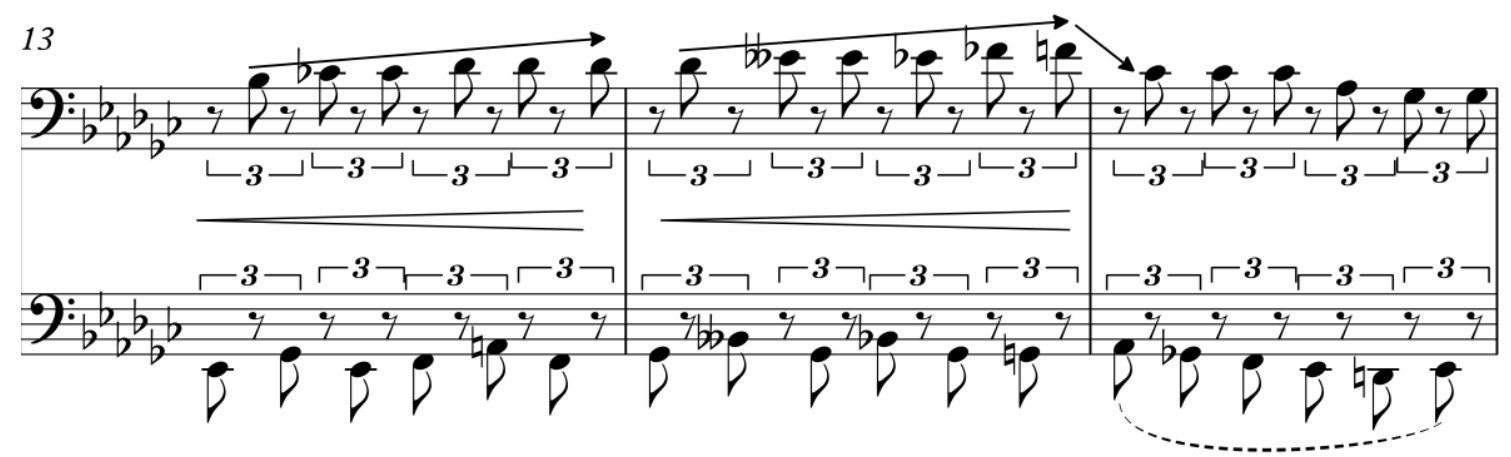

Figura 6: Comp. 13-15 - Segunda tentativa da melodia para se desvencilhar do baixo

Apesar da relação de oposição rítmica permanecer durante toda a peça, a partir do compasso 15 surgem mostras de um possível diálogo, pois por um momento o baixo abandona o seu perfil angular, adotando um movimento em graus conjuntos descentes do $4^{\circ}$ ao $1^{\circ}$ graus da escala de Mibm, passando pela sensível, $7^{\circ}$ grau maior. Em seguida, no compasso 16, enquanto o baixo volta para a sua essência angular e oscilante, com a progressão $4^{\circ}-1^{\circ}-4^{\circ}-5^{\circ}-1^{\circ}$ graus, a melodia fica estática como que indicando qual deveria ser o comportamento do baixo, o que é prontamente assumido no compasso seguinte. A partir deste momento, com o baixo completamente imobilizado, a melodia finalmente conquista a sua independência completando a escala de Mibm com o movimento ascendente do $5^{\circ}$ ao $7^{\circ}$ graus, ainda que de forma tímida, por sua dinâmica em decrescendo, rumo ao piano (vide Figura 7). 


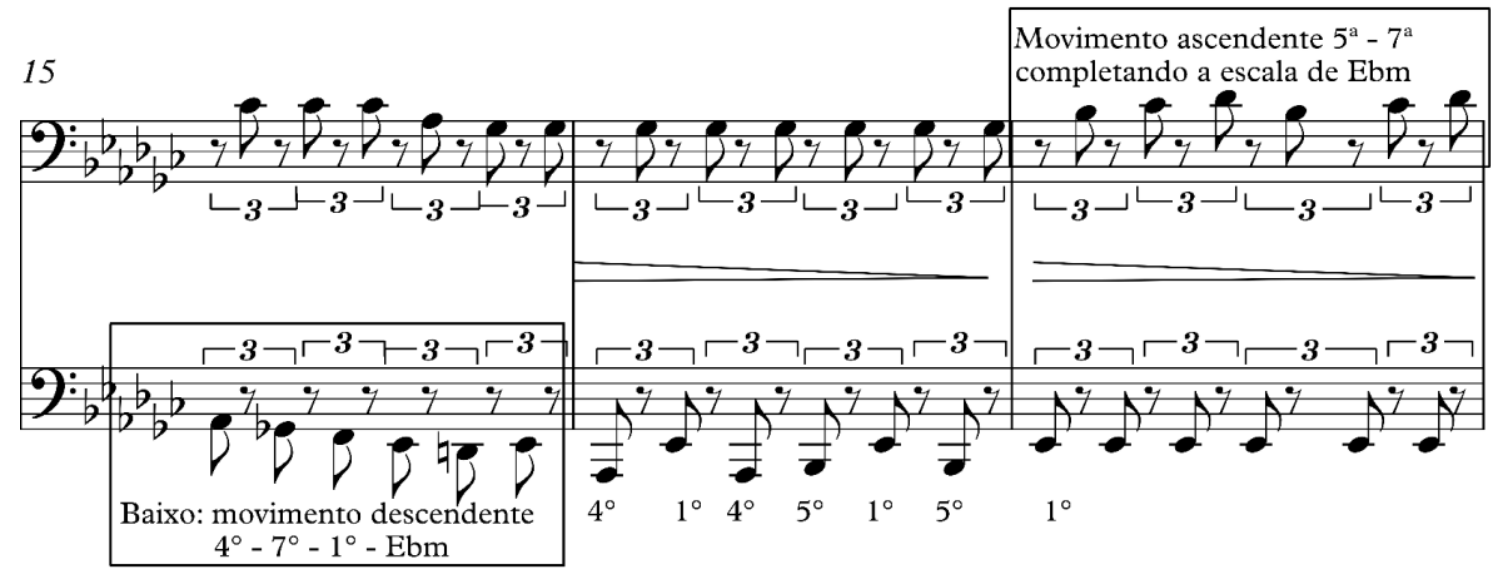

Figura 7: Compassos 15-17 - Indicativo de diálogo entre as isotopias

Na conclusão do movimento (vide Figura 8), verifica-se que o baixo continua estático ou inerte diante da melodia, que finalmente se lança à sua plena individuação. A diferenciação melódica conquistada é, entretanto, violada no último e único momento no qual as duas isotopias coincidem na nota Mib.

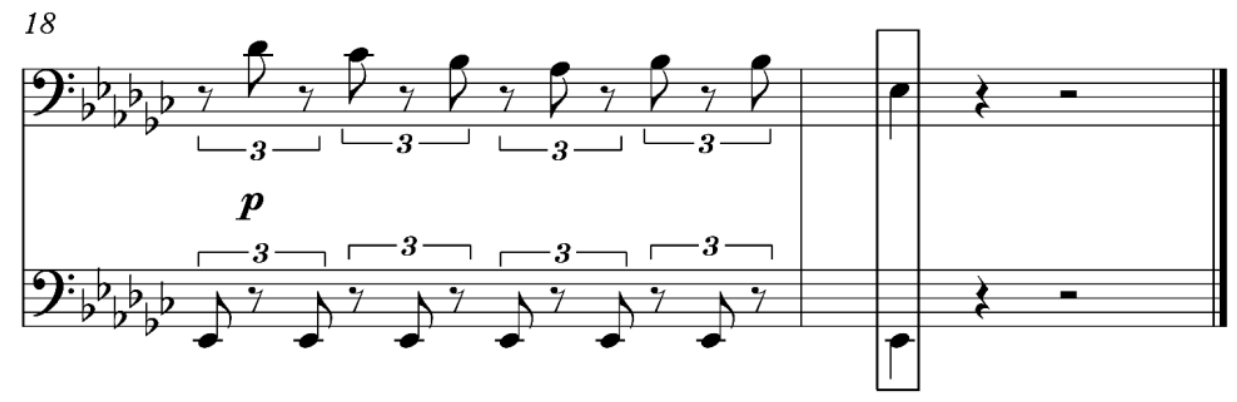

Figura 8: Compassos 18-19 - Conclusão do movimento

\section{7 - Arquétipo Narrativo}

A partir das informações levantadas, tanto a partir de revisão bibliográfica sobre a peça como pela análise empreendida, pode-se concluir que a hierarquia prevista pelo conceito de arquétipo narrativo é concentrada na aparente textura monofônica da peça. Aprofundando-se em sua estrutura, no entanto, verifica-se que as duas isotopias, duas vozes em registros de altura distintos, cumprindo a função de baixo e melodia, relacionam-se, no nível atorial, de maneira contrapontística. Há, portanto, uma polifonia latente na aparente homofonia do prelúdio. $\mathrm{O}$ esforço de individuação entre estas duas vozes, incorporado principalmente pela melodia, assume a frente da transgressão polifônica contra a ordem homofônica. 
Diante deste quadro, tendo a melodia assumido sua independência nos últimos compassos, é possível aproximar tipologicamente esta narrativa ao arquétipo do romance. Entretanto, o desfecho com as duas vozes na nota Mib volta a borrar a identidade entre as duas vozes. O alto nível de convencionalida de em se terminar uma peça desta maneira reforça ainda mais a reincorporação da narrativa em uma hierarquia cultural. Esta aparente derrota da transgressão, todavia, não descaracteriza o enquadramento arquetípico, já que a ambiguidade do desfecho é típica das narrativas de romances, funcionando como uma espécie de epílogo dramático potencializador da vitória do herói. Um correlato literário que pode ser evocado para exemplificar este fenômeno é o romance O Vermelhoe o Negro de Stendhal. Nele, o protagonista, Julien Sorel, após ter alcançado o zênite da sua ascensão hierárquica, fruto de seus empreendimentos individuais, e ter vencido a ordem com a qual se debatia, é levado, por uma revelação de sua examante, a condenação à morte. Julien, assim como a célebre decisão de Sócrates em beber a cicuta ao invés de sobreviver a custo da traição de seus próprios valores morais, mantém a solidez de seu caráter até o momento da sua decapitação, servindo sua morte mais como coroação de sua empreitada ambiciosa do que derrota diante de seus inimigos.

\section{8 - Conclusão}

A narratividade do prelúdio N.14 de Chopin revela um aspecto capital para o pensamento romântico: a emergência do sujeito radicado na singularidade. Benedito Nunes (1978, p.58) afirma, sobre a capacidade expansiva e a força irradiante do $E u$ no romantismo:

[...] o Eu, [...], assegurou um primado ontológico à interioridade, à vida interior, que foi sinônimo de profundeza, espiritualidade, elevação e liberdade no vocabulário do Romantismo, quando não significou também o "solo sagrado" da verdadeira vida, o recesso do ideal, de onde sentimento religioso brota, onde a perfeição moral se abriga e a arte começa.

A cisão do homem do século XIX, na alvorada da modernidade, consigo mesmo levou a ruptura com as convenções poéticas e filosóficas do classicismo, afastando as ideias de comunhão perfeita entre o homem e natureza. Diante deste estilhaçamento ontológico, impõem-se a necessidade de elaboração de um novo tipo de sujeito, não mais guiado por modelos ideais de sensibilidade importados de matrizes greco-latinas, mas sim situando o "eu" como meio de reflexão infinito. Não é à toa que elementos como originalidade, intuição, criação e imaginação guiaram o pensamento romântico. 
A pluralidade de vozes em uma textura polifônica latente na aparente homofonia da peça analisada incorpora essa questão de forma bastante emblemática. Diante de uma aparente unidade orgânica, um estilhaçamento fenomenológico pulsa de forma cada vez mais intenso até a evidente separação das vozes no desfecho do prelúdio. A singularidade vence. Pode-se estabelecer alguns binarismos para iluminar o conflito dessa peça como: homogeneidade $x$ heterogeneidade; homofonia $\mathrm{x}$ polifonia; unidade $\mathrm{x}$ diversidade; dependência $\mathrm{x}$ independência.

Diante desta análise, é possível perceber que a metodologia analítica proposta por Almén possibilita a investigação de questões da significação musicais que não se reportam somente à análise musical tradicional, permitindo um avanço na área ao fundamentar um campo epistemológico (ainda imaturo no Brasil) que dialoga com outras áreas de conhecimento e de produção estética, podendo, dessa maneira, lançar um olhar fresco sobre o cânone.

Por fim, um aspecto importante que pode ser elucidado por estudos sobre narratividade musical diz respeito às consequências destes na performance musical. Na peça analisada neste artigo, considerando a partitura que se teve acesso, uma indicação sublinhava que Chopin, na partitura original, riscou a palavra Allegro e a substituiu por Largo (Figura 9), entretanto essa alteração não prevaleceu em outras edições dos Prelúdios, constando em alguns casos apenas como notas de rodapé ou comentário ${ }^{2}$.

Independente da tradição de performance desta peça, uma análise como a empreendia revela que a estrutura narrativa é mais adequadamente revelada com andamento Largo, como se pode verificar nas diferenças entre as gravações de Rudolf Serkin ${ }^{3}$ e Arthur Rubinstein por exemplo, atestando, assim, a importância da análise narrativa de uma peça no subsídio para sua boa performance.

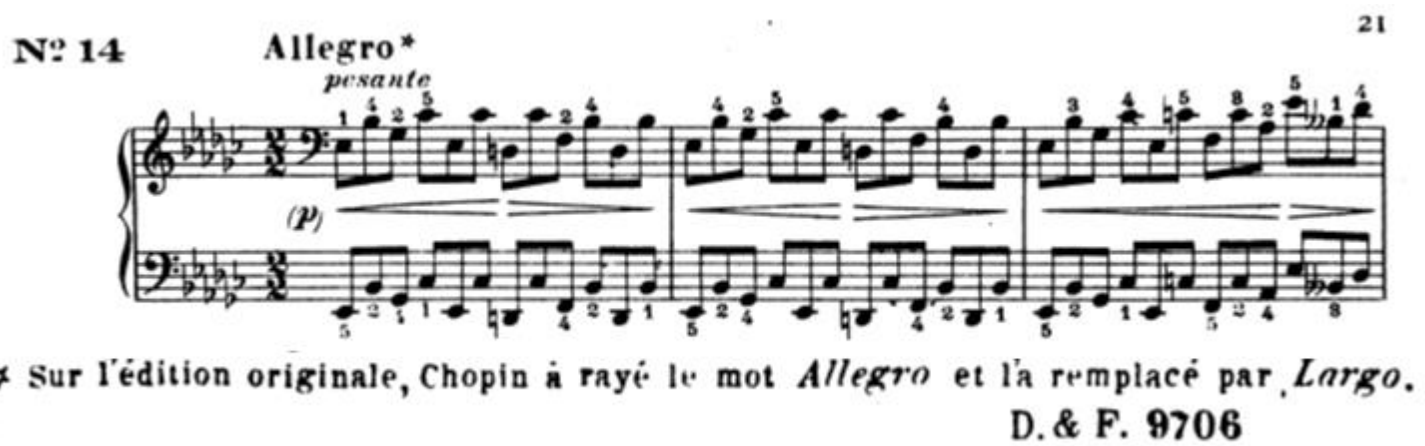

Figura 9: Compassos 1-2 - Edizioni Curci, revisione critico-tecnica di Alfredo Casella

2 Como por exemplo em: F. Chopin - Preludi, revisione critico-tecnica di Alfredo Casella. Milano: Edizioni Curci. IMSLP406459-PMLP02344.

${ }^{3}$ Rudolf Serkin, Chopin Preludes, 10/17/1979, Tokyo: Canal op106. Áudio, 42'47". Disponível em: https://youtu.be/34uOX_uGL30. Acesso em junho 2017. 


\section{Referências}

1. Almén, Byron. 2008. A Theory of Musical Narrative. USA: Indiana University Press.

2. Greimas, Algirdas J. 1973. Semântica estrutural. Tradução de H. Osakape e I. Blikstein. São Paulo: Cultrix/EdUSP.

3. Hood, Alison. 2014. Interpreting Chopin: Analysis and Performance. Burlington: Ashgate.

4. Klein, Michael L. 2009. Ironic Narrative, Ironic Reading. Journal of Music Theory, vol. 53, no 1, p. 95-136.

5. Leikin, Anatole. 2015. The Mistery of Chopin's Preludes. Burlington: Ashgate.

6. Leite, Ricardo L. 2009. Isotopia e metaforização textual. Gragoatá no 26, p. 121134.

7. Meier, Marilyn Anne. 1993. Chopin twenty-four Preludes opus 28. Doctor of Creative Arts Dissertation, School of Creative Arts, University of Wollongong. http://ro.uow.edu.au/theses/947

8. Nunes, Benedito. 1978. A visão romântica. In: O romantismo. Guinsburg, Jacó (Org.) São Paulo: Perspectiva.

9. Ogden, Aeron. 2009. Tempo, Effect and the Emergence of Line in Chopin's Prelude Op. $28 n^{\underline{0}}$ 14. https://pt.slideshare.net/AeronOgden/tem po-effect-and-theemergence-of-line-in-chopins-prelude-op-28-no-14. Acesso em 15/05/2017.

10. Tarasti, Eero. 1994. A Theory of Musical Semiotics. Bloomington: Indiana University Press.

11. Todorov, Tzvetan. 1971. Poética da prosa. (Trad. M. de S. Cruz). Lisboa: Edições 70. 